\title{
Improved Mechanical, Anti-UV Irradiation, and Imparted Luminescence Properties of Cyanate Ester Resin/Unzipped Multiwalled Carbon Nanotubes/Europium Nanocomposites
}

\author{
Na Yang ${ }^{1}$, Xiaohua Qi ${ }^{1}$, Di Yang ${ }^{1}$, Mengyao Chen ${ }^{1}$, Yao Wang ${ }^{1}$, Linjun Huang ${ }^{1}$, Olga Grygoryeva ${ }^{2}$, \\ Peter Strizhak ${ }^{3}$, Alexander Fainleib ${ }^{2}$ (i) and Jianguo Tang $1, * \mathbb{( 1 )}$
}

1 Institute of Hybrid Materials, National Centre of International Joint Research for Hybrid Materials Technology, National Base of International Sci. \& Tech. Cooperation on Hybrid Materials, Qingdao University, 308 Ningxia Road, Qingdao 266071, China; 17669490805@163.com (N.Y.); qixiaohua0930@163.com (X.Q.); yd130102@163.com (D.Y.); chenmengyao210@163.com (M.C.); wangyaoqdu@126.com (Y.W.); huanglinjun@qdu.edu.cn (L.H.)

2 Institute of Macromolecular Chemistry of the National Academy of Sciences of Ukraine, 02068 Kyiv, Ukraine; grigoryevaolga@i.ua (O.G.); fainleib@i.ua (A.F.)

3 B.L.V. Pysarzhevskii Institute of Physical Chemistry, National Academy of Sciences of Ukraine, 31 Prosp. Nauky, 03028 Kyiv, Ukraine; pstrizhak@hotmail.com

check for updates

Citation: Yang, N.; Qi, X.; Yang, D.; Chen, M.; Wang, Y.; Huang, L.; Grygoryeva, O.; Strizhak, P.; Fainleib, A.; Tang, J. Improved Mechanical, Anti-UV Irradiation, and Imparted Luminescence Properties of Cyanate Ester Resin/Unzipped Multiwalled Carbon Nanotubes/Europium Nanocomposites. Materials 2021, 14 , 4244. https://doi.org/10.3390/ ma14154244

Academic Editor: Antonio Di Bartolomeo

Received: 22 June 2021

Accepted: 27 July 2021

Published: 29 July 2021

Publisher's Note: MDPI stays neutral with regard to jurisdictional claims in published maps and institutional affiliations.

Copyright: ( $\odot 2021$ by the authors Licensee MDPI, Basel, Switzerland. This article is an open access article distributed under the terms and conditions of the Creative Commons Attribution (CC BY) license (https:// creativecommons.org/licenses/by/ $4.0 /)$.
* Correspondence: tang@qdu.edu.cn

\begin{abstract}
Cyanate ester resin (CER) is an excellent thermal stable polymer. However, its mechanical properties are not appropriate for its application, with brittle weakness, and it has poor functional properties, such as luminescence. This work innovatively combines the luminescence property and the improved mechanical properties with the inherent thermal property of cyanate ester. A novel nanocomposite, CER/uMWCNTs/Eu, with multi-functional properties, has been prepared. The results show that with the addition of $0.1 \mathrm{wt} . \%$ of uMWCNTs to the resin, the flexural strength and tensile strength increased $59.3 \%$ and $49.3 \%$, respectively. As the curing process of the CER progresses, the injected luminescence signal becomes luminescence behind the visible (FBV). The luminescence intensity of CER/uMWCNTs/Eu was much stronger than that of CER/MWCNTs/Eu, and the luminescence lifetime of CER/MWCNTs/Eu and CER/uMWCNTs/Eu was $8.61 \mu$ s and $186.39 \mu \mathrm{s}$, respectively. FBV exhibited great potential in the embedment of photon quantum information. Therefore, it can be predicted that CER/uMWCNTs/Eu composites will not only have a wide range of applications in sensing, detection, and other aspects, but will also exhibit great potential in the embedding of photon quantum information.
\end{abstract}

Keywords: cyanate ester resin; unzipped multiwalled carbon nanotubes; europium; nanocomposites; structure-property relationships; ultraviolet aging; luminescence

\section{Introduction}

Cyanate ester resin (CER) is an excellent thermal stable polymer, with a unique triazine ring network structure, which can be used at high temperatures for a long time. Therefore, it is widely applied in various fields, such as aerospace, microelectronics packaging field, and so on [1-4]. However, its mechanical properties are not appropriate for its application, with brittle weakness, and it has poor functional properties, such as luminescence [5-7]. Therefore, it is important to find an additive that can not only improve its mechanical properties such as toughness, but also increase its functional properties.

Multiwalled carbon nanotubes (MWCNTs) have excellent structural characteristics, are easy to functionalize, and can be used as reinforcement materials to improve the performance of polymer materials [8-11]. CER/MWCNTs nanocomposites have been recently developed and studied by several teams [12-20]. The catalytic effect of MWCNTs on CER polymerization was fixed, and CER/MWCNTs nanocomposites with improved 
mechanical and thermal properties and electrical and thermal conductivity have been elaborated. However, the matrix reinforcement of MWCNTs is not significant because the contact area between the carbon nanotubes and the matrix is limited, and the outermost nanotubes prevent the inner tubes from contacting the polymer matrix. [21]. Kosynkin et al. reported a representative way to form unzipped multiwalled carbon nanotubes (uMWCNTs) [22]. Since then, many reports have begun to use uMWCNTs as fillers to strengthen polymer composites [23,24]. Those demonstrated that uMWCNTs have outstanding physical enhancement properties and are superior to those of MWCNTs [25,26]. As a filler, carbon nanotubes can not only improve the brittleness of polymer, but also functionalize polymer materials.

Cyanate resins are commonly used in aerospace applications, hence UV aging resistance is also an important indicator to measure their performance [27]. In addition, the material can also be damaged by ultraviolet radiation and other environmental factors in their actual use, which will cause aging of the material. The aging of polymer material is an important factor affecting the safety of a sealed cabin, which requires it to have the ability to resist solar radiation, the thermal cycle, electronic radiation, and other factors in space [28]. Cyanate ester resin itself has excellent UV aging resistance. The effect of uMWCNTs on the UV aging performance of cyanate resin was also studied in this paper.

Furthermore, we also injected luminescence properties into the cyanate ester resin matrix. Just a few publications have reported the combination of the luminescent properties of lanthanide complexes with heat-resistant polymers [29-31]. We have innovatively combined lanthanide complexes with CER to obtain light-emitting and heat-resistant polymer composites. After curing, the luminescence emission spectrum of resin usually has a peak at $500 \mathrm{~nm}$, which is a characteristic peak of polymer materials containing aromatic rings. However, the new luminescence signal of the lanthanide complex we injected is different from the original peak of the resin. With the formation of a cyanate ester network during curing, the injected luminescence signal changed to luminescence behind the visible (FBV). FBV has great application potential in the embedment of photon quantum information.

As a kind of special luminescence materials, lanthanide complexes are often combined with various organic or inorganic materials to prepare hybrid materials for practical use. In recent years, polymers, as a kind of material with excellent mechanical properties, are also combined with lanthanide complexes. However, pure lanthanide complexes and polymer matrix have unstable luminescence properties. Therefore, we first attached the lanthanide compound on the side wall of carbon nanotubes to prepare luminescence carbon nanotubes [32,33]. For example, Wu et al. coated the multiwalled carbon nanotubes by lanthanide $\left(\mathrm{Eu}^{3+}, \mathrm{Tb}^{3+}\right)$ complexes and obtained luminescence materials with excellent luminescence stability through a simple in situ synthesis method [34]. In addition, functional groups on a surface of carbon nanotubes can also enhance the interface interaction with polymer [35]. Thus, excellent mechanical and processing properties of the matrix and luminescence of lanthanide complex are combined to obtain a new type of luminescent materials with excellent mechanical and luminescence properties.

Herein, a novel kind of cyanate ester resin/unzipped multiwalled carbon nanotubes (uMWCNTs) luminescent nanocomposite was developed, which combined the excellent mechanical properties of heat resistance, $\mathrm{UV}$ aging resistance of the polymer nanocomposite and the luminescence properties of the lanthanide complex. First, the enhancement effect of uMWCNTs on the toughness and thermal properties of CER was determined. On this basis, we added luminescence signal to the composite material, resulting in the composite with unique combination of toughness, thermal, and luminescence properties. It could be predicted that thermally resistant polymer hybrid luminescent materials would be widely used in sensing, detection, and hazard prediction. 


\section{Materials and Methods}

\subsection{Materials}

The cyanate ester resin monomer (Bisphenol A dicyanate ester, DCBA) was supplied from Kaixin New Material Technology Co., Ltd. (Liyang, China). Multiwalled carbon nanotubes (MWCNTs, length: 0.5-2 $\mu \mathrm{m}$, diameter: $50 \mathrm{~nm}$ ) were bought from Xianfeng Nano Material Technology Co., Ltd. (Nanjing, China). $\mathrm{EuCl}_{3}$ (99.99\%), TTA (99\%), and phen (99.99\%) were procured from Maclean Biochemical Technology Co., Ltd. (Shanghai, China). Acetone, $\mathrm{H}_{2} \mathrm{SO}_{4}(98 \%), \mathrm{H}_{2} \mathrm{O}_{2}(30 \%), \mathrm{HCl}(36 \%)$ and $\mathrm{KMnO}_{4}$ were also received from Maclean Biochemical Technology Co., Ltd (Shanghai, China).

\subsection{Methods}

2.2.1. Preparation of Unzipped Multiwalled Carbon Nanotubes (uMWCNTs) and MWCNTs/Eu and uMWCNTs/Eu Composites

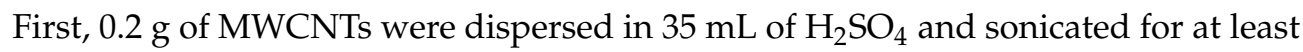
$10 \mathrm{~h}$. Then, $1 \mathrm{~g} \mathrm{KMnO}_{4}$ was added in several times under magnetic stirring, and then raised the temperature to $50{ }^{\circ} \mathrm{C}$, and held for $1 \mathrm{~h}$. After that, quickly poured the mixture into a beaker filled with $\mathrm{H}_{2} \mathrm{O}_{2}$ ice. If bubbles were generated, added $0.2 \mathrm{~mL}$ of $\mathrm{H}_{2} \mathrm{O}_{2}$ solution and repeated the step of adding $\mathrm{H}_{2} \mathrm{O}_{2}$ solution multiple times until no bubbles were generated. Then, the mixed solution was centrifuged and washed once with dilute $\mathrm{HCl}(10 \%)$ and deionized water several times until the $\mathrm{pH}$ of the mixed solution was neutral, and then dried in oven at $60{ }^{\circ} \mathrm{C}$. The resulting black powder was unzipped multiwalled carbon nanotubes, coded as uMWCNTs.

Next, the MWCNTs/Eu and uMWCNTs/Eu composites were prepared. Appropriate amounts of MWCNTs or uMWCNTs were uniformly dispersed in ethanol at $60^{\circ} \mathrm{C}$. Then,

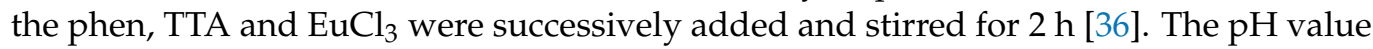
was adjusted to 11, and the luminescence intensity was the highest when the $\mathrm{pH}$ value was 11 [37]. The mixture was washed to remove excess Eu(TTA) $)_{3}$ phen complexes and dried. The uMWCNTs/Eu composites, which had a europium complex on the surface of uMWCNTs, have been obtained.

\subsubsection{Preparation of CER/uMWCNTs and CER/uMWCNTs/Eu Nanocomposites}

uMWCNTs were dispersed $(1 \mathrm{mg} / \mathrm{mL})$ by ultrasonication in acetone at room temperature for $30 \mathrm{~min}$. Then $\mathrm{CE}$ monomer added to the above acetone solution and stirred vigorously for $2 \mathrm{~h}$ at $100{ }^{\circ} \mathrm{C}$ [38]. The mixed solution was dried in an oven for $24 \mathrm{~h}$ at $80{ }^{\circ} \mathrm{C}$ to remove acetone and cast into a preheated mold coated for curing. The CER/ uMWCNTs nanocomposite was synthesized using step by step curing schedule consisted of the following stages: $1 \mathrm{~h}$ at $120^{\circ} \mathrm{C}, 1 \mathrm{~h}$ at $140{ }^{\circ} \mathrm{C}, 2 \mathrm{~h}$ at $160^{\circ} \mathrm{C}, 2 \mathrm{~h}$ at $180^{\circ} \mathrm{C}, 2 \mathrm{~h}$ at $200^{\circ} \mathrm{C}$, $4 \mathrm{~h}$ at $230{ }^{\circ} \mathrm{C}$ and post curing via $1 \mathrm{~h}$ at $250^{\circ} \mathrm{C}$ [39]. The concentration of uMWCNTs was $0.1 \mathrm{wt} . \%$. The preparation method used for CER/uMWCNTs nanocomposite synthesis is schematically shown in Figure 1.

The CER/uMWCNTs/Eu nanocomposite containing $0.1 \mathrm{wt} . \%$ of uMWCNTs/Eu was prepared similarly.

\subsubsection{UV Irradiation Exposure}

In the process of actual use, the material will be affected by ultraviolet radiation and other environmental factors, which will cause the aging of the material. Samples of the nanocomposites were exposed to UV radiation at $50{ }^{\circ} \mathrm{C}$ in an accelerated climate chamber which was self-made in the laboratory, equipped by four rows of UV lamps with a UV radiation wavelength of $340 \mathrm{~nm}$ each and the intensity was $0.71 \mathrm{~W} / \mathrm{m}^{2}$ [40]. The total dose of UV irradiation applied was $9.6 \times 107 \mathrm{~J} / \mathrm{m}^{2}$ (40 days of exposure). The sample was $5 \mathrm{~cm}$ away from the UV lamp and placed in parallel. 


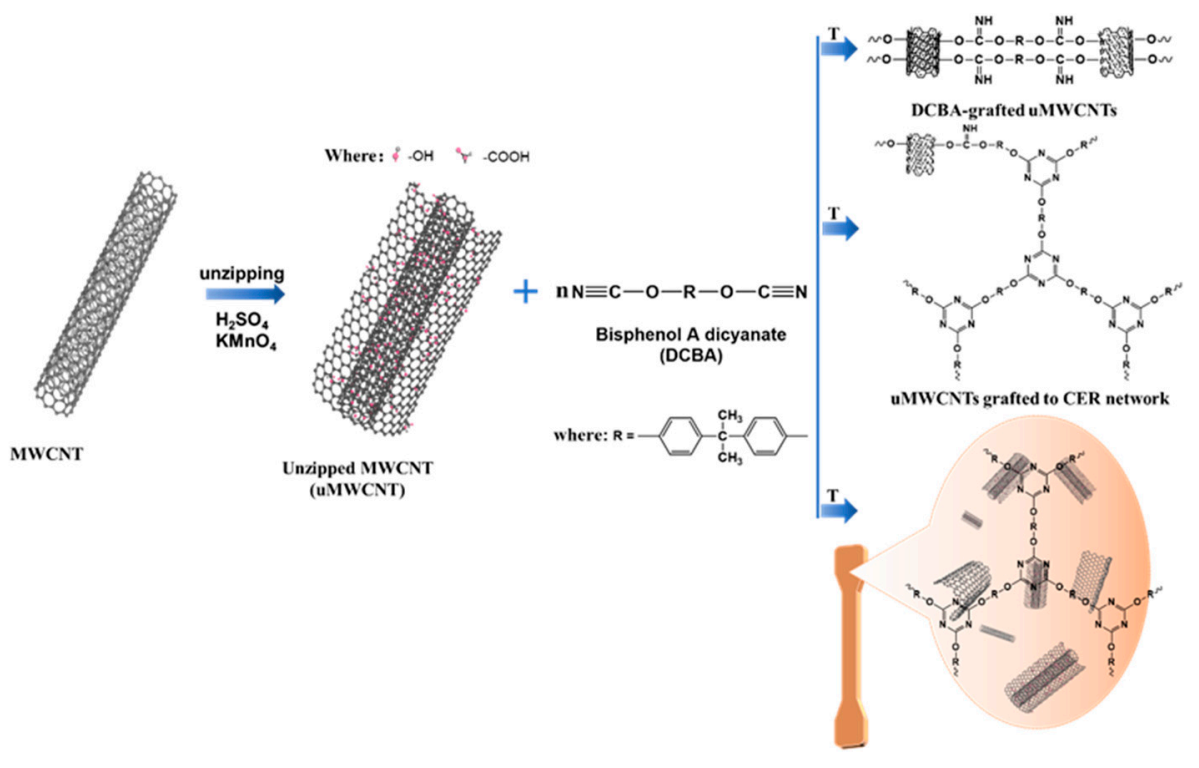

Figure 1. Schematic illustration of the preparation process used for CER/uMWCNTs nanocomposites.

\subsection{Characterization}

Fourier transformed infrared spectroscopy (FTIR, MAGNA-IR 5700) (Thermo Nicolet Corporation, Waltham, MA, USA), X-ray diffraction (XRD, D8 Advance) (Bruker, Karlsruhe, Germany), Raman (Almega Thermo Nicolet) (Thermo Nicolet Corporation, Waltham, MA, USA) and X-ray photoelectron spectroscopy (XPS, ESCALAB-210) (Thermo Fisher Scientific, Waltham, MA, USA) were applied to characterize the structure of carbon nanotubes.

The cross section of the nanocomposites was characterized by scanning electron microscope (SEM, JEOL 6460) (JEOJ, Kyoto, Japan). The MWCNTs and unzipped MWCNTs were characterized using Transmission Electron Microscopy (TEM, JEM-F2100) (JEOJ, Kyoto, Japan). The outer diameter of MWCNTs and uMWCNTs were measured using Nano Measurer software (Nano Measurer 1.2, Shanghai, China). The number of nanotubes of each type was equal, and at least 50 nanotubes were measured. The flexural and tensile properties of the composites were measured with a universal testing machine (CMT4304GD) (MTS, Jinan, China); Sample size was $75 \mathrm{~mm} \times 5 \mathrm{~mm} \times 4 \mathrm{~mm}$, and five samples were measured for each nanocomposite. The thermal behavior was characterized using Differential Scanning Calorimeter (DSC, DSC214 Polyma) (NETZSCH, Cologne, Germany) and Thermogravimetric analysis (TGA, SDT Q600) (TA Instruments, New Castle, PA, USA). The initial degradation temperature $\left(\mathrm{T}_{\mathrm{di}}\right)$ was determined as the $5 \%$ weight loss temperature. Luminescence intensity and lifetime were recorded on the were recorded on Edinburgh luminescence spectrofluorometer (FLS980-STM) (Edinburgh Instruments, Edinburgh, United Kingdom).

\section{Results and Discussion}

\subsection{Structure of uMWCNTs, MWCNTs/Eu and uMWCNTs/Eu}

Unzipped multiwalled carbon nanotubes (uMWCNTs) is a portrayal description in references/publications [22], which indicates the geometric change of CNTs. In this unzipping process, the oxidation of pristine CNTs is the chemical cause to initiate this morphological structural change of MWCNTs. It should be noted that in this process, the one-dimensional MWCNTs are destroyed and changed into open morphological structures with different geometric shapes, as shown in Figure 2. The TEM images of pristine MWCNTs and unzipped MWCNTs show that the morphology of the carbon nanotubes changed significantly after their unzipping. As shown in Figure 2, the pristine MWCNTs can be seen with smooth outer contours and the tubular structure is obvious. Compared with pristine MWCNTs, the length of uMWCNTs became shorter after strong oxidation method processing, and the outer walls were partially loosened or unwrapped, or even fell off from the surface of 
the nanotubes to form graphene nanosheets, thus increasing the surface area of MWCNTs. Instead of forming flat graphene sheets, however, they show a tubelike structure. The size distribution of the outer width for the MWCNTs and uMWCNTs in the diagrams inside the corresponding TEM images also illustrated this phenomenon. Figure 2 shows that the pristine MWCNTs have inherent hollow tubular structure with the average outer width of $\mathrm{D}=42.68 \pm 5.06 \mathrm{~nm}$, while the average outer width of uMWCNTs is $\mathrm{D}=83.0 \pm 1.53 \mathrm{~nm}$. One can see that the width of uMWCNTs is almost twice compared to that of MWCNTs, indicating effective unzipping [22]. The increase of the width of carbon nanostructures not only provided a larger surface area for the binding of polymer resin to carbon nanotubes, but also increased the number of groups available on the edge and surface of MWCNTs for further improvement of effective matrix/filler interaction and the dispersion stability.

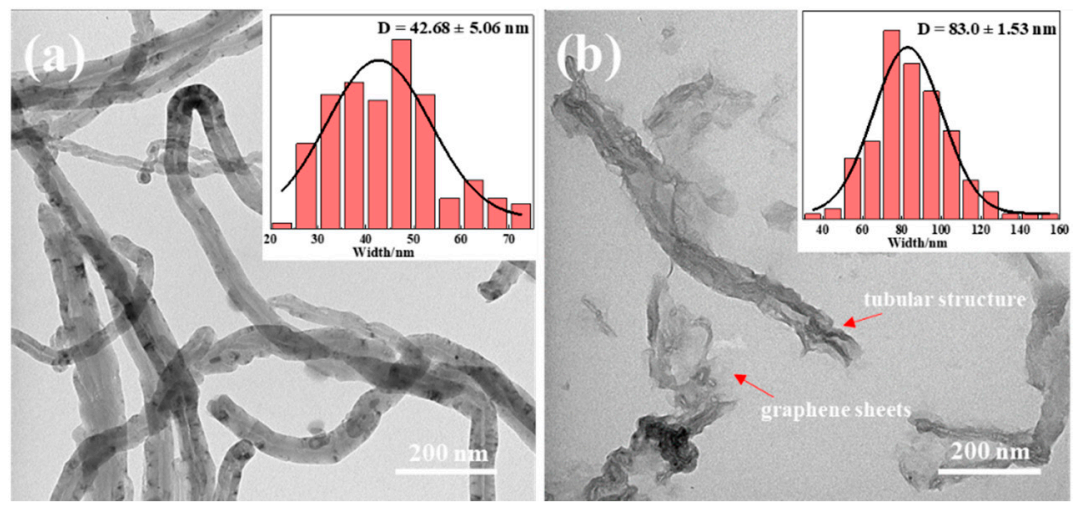

Figure 2. TEM images of (a) pristine MWCNTs, and (b) uMWCNTs.

Figure 3a illustrates the surface structure of MWCNTs characterized by FTIR. The FTIR spectra of uMWCNTs show two strong absorption peaks at $3400 \mathrm{~cm}^{-1}$ and $1224 \mathrm{~cm}^{-1}$, which correspond to the stretching and bending vibration of $-\mathrm{OH}$, respectively. The $\mathrm{C}=\mathrm{O}$ and $\mathrm{C}-\mathrm{OH}$ in - $\mathrm{COOH}$ exhibited the stretching vibrations at $1725 \mathrm{~cm}^{-1}$ and $1397 \mathrm{~cm}^{-1}$ [4143]. The FTIR spectra illustrated that the unzipped MWCNTs had oxygen-containing functional groups formed at the oxidation by strong oxidants such as potassium permanganate, thus contributing to the interaction between the resin and the filler and to effective dispersing of the latter in the matrix.
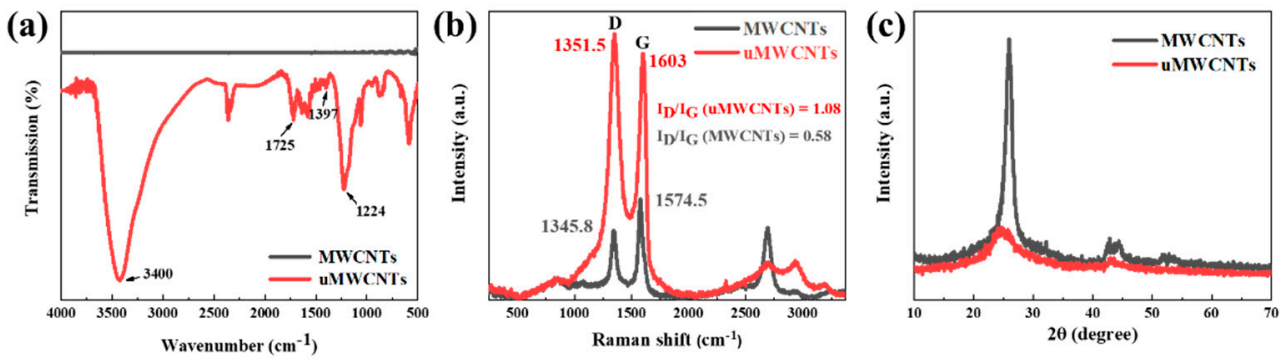

Figure 3. FTIR spectra (a), Raman spectra (b) and XRD patterns (c) of MWCNTs and uMWCNTs.

Raman spectra (Figure 3b) demonstrates that the pristine MWCNTs shows a D band at $1346 \mathrm{~cm}^{-1}$, which is attributed to the defects on the surface or edge of uMWCNTs and the disordered structure of graphite in the MWCNTs, as well as a G band at $1574 \mathrm{~cm}^{-1}$ attributed to the $\mathrm{C}$ atom $\mathrm{sp}^{2}$ hybridized in-plane stretching vibration [44]. Compared with the MWCNTs, the shape and intensity of the 2D peak at $2700 \mathrm{~cm}^{-1}$ of uMWCNTs obviously changed. The value of $\mathrm{I}_{\mathrm{D}} / \mathrm{I}_{\mathrm{G}}(\mathrm{R})$ is often used to exhibit the degree of functionalization of MWCNTs [45]. The $R$ value represented the degree of graphitization of carbon nanotubes. It can be seen from Figure $3 \mathrm{~b}$ that the $\mathrm{R}$ value increases from 0.58 to 1.08 after unzipping, which reveals that a large number of defects [46] and functional groups are formed in the 
MWCNTs at unzipping, and the size of the in-plane $\mathrm{C} \mathrm{sp}{ }^{2}$ domains decreases, destroying the original ordered structure.

The XRD pattern of the MWCNTs shows the presence of a peak at $2 \theta=25.9^{\circ}$, which is the corresponding graphite surface with spacing of (002) plane and corresponding $\mathrm{d}$ spacing of $0.34 \mathrm{~nm}$. After unzipping, the position of the main peak moved slightly to the position of $2 \theta=24.7^{\circ}$, and the d-spacing became $0.36 \mathrm{~nm}$. The peak of XRD spectrum at $2 \theta=42.3^{\circ}$ represented the characteristic diffraction peak of plane (100). This indicated that MWCNTs were unzipped to uMWCNTs and the most of the MWCNTs structure were changed. Due to the introduction of more oxygen-containing groups between adjacent layers, the d-spacing increases and the dense graphene layer falls off loosely.

To further investigate the changes of functional groups before and after the oxidation of MWCNTs, we characterized MWCNTs and uMWCNTs via XPS. The ratio of the content of carbon to the content of oxygen in XPS spectrum $(\mathrm{O} / \mathrm{C}$ ratio) could characterize the degree of oxidation of carbon materials. The O/C ratio of MWCNTs and uMWCNTs is 0.0041 and 0.1593 respectively. The results show that the $\mathrm{O} / \mathrm{C}$ ratios of uMWCNTs were higher than that of MWCNTs, indicating that the oxidation degree of uMWNTs increased. In the XPS spectra (Figure 4), the O content of MWCNTs is near zero, which can be considered to be caused by the moisture in the air. The peak intensity of O1s of uMWCNTs is much higher than that of MWCNTs, and can be divided into $532.3 \mathrm{eV} \mathrm{C}-\mathrm{O}$, $533.2 \mathrm{eV} \mathrm{C}=\mathrm{O}$. It proved that the surface of CNTs is modified with $\mathrm{O}$.

(a)
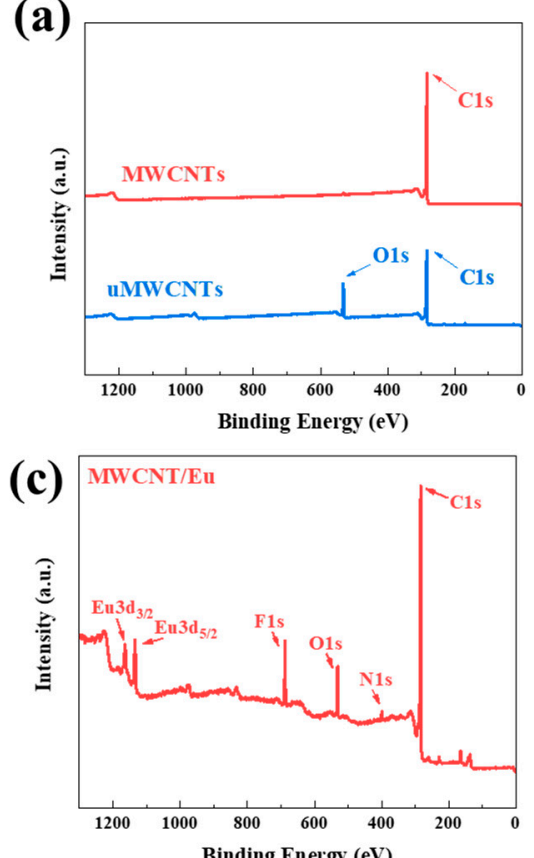

(e)

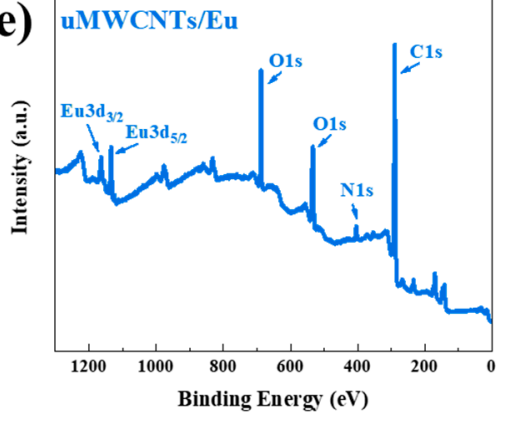

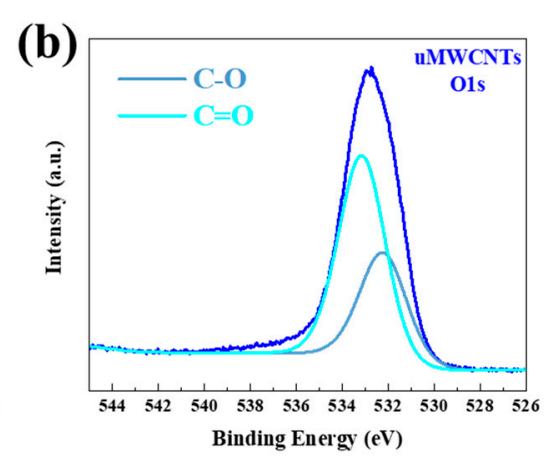
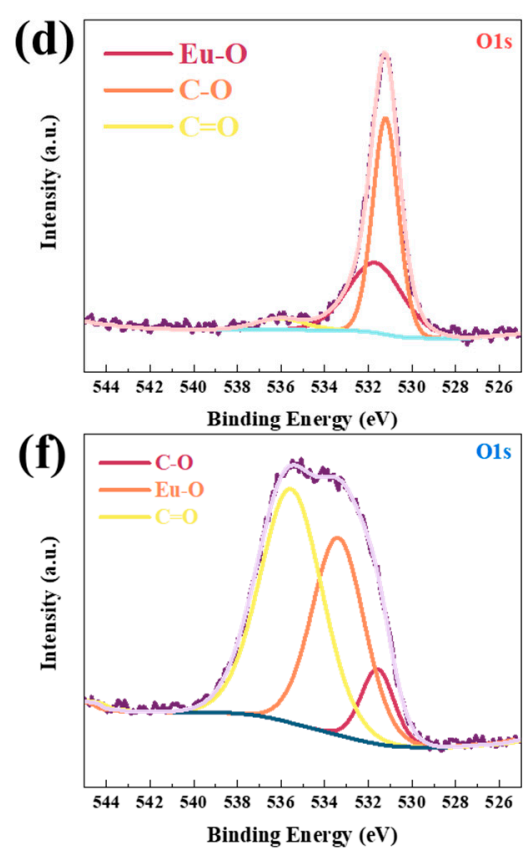

Figure 4. XPS spectra of MWCNTs (a); uMWCNTs (b,c); MWCNTs/Eu (d,e); uMWCNTs/Eu (f). 
In the uMWCNTs /Eu spectra, Eu ${ }^{3+}$ shows two peaks, namely $\mathrm{Eu}_{3} \mathrm{~d}_{5 / 2}$ at about $1135 \mathrm{eV}$ and $\mathrm{Eu}_{3} \mathrm{~d}_{3 / 2}$ at about $1165 \mathrm{eV}$, which proved the existence of the Eu trivalent state. In addition, characteristic peaks of N1s and O1s were also observed in Figure 4e,f. According to the peak differentiation of O1s, there is an $\mathrm{Eu}-\mathrm{O}$ peak near $533 \mathrm{eV}$, which indicated the existence of Eu in uMWCNTs/Eu and the formation of bonding with CNTs. The $\mathrm{F}$ and $\mathrm{N}$ elements in the sample also confirmed the existence of $\mathrm{Eu}(\mathrm{TTA})_{3}$ phen in uMWCNTs/Eu. It can also be seen from the contents of each element in Table 1 that the contents of $\mathrm{Eu}, \mathrm{F}$ and $\mathrm{N}$ elements in $\mathrm{Eu}(\mathrm{TTA})_{3}$ phen in uMWCNTs/Eu are higher than those in MWCNTs/Eu, indicating that the content of europium complex in uMWCNTs/Eu is higher than that in MWCNTs/Eu. This is in connection with the increased surface area of uMWCNTs and the increase of groups on the surface and edge, which could adsorb more lanthanide metal complexes.

Table 1. XPS analysis results of MWCNTs/Eu, uMWCNTs/Eu, MWCNTs/Eu and uMWCNTs/Eu.

\begin{tabular}{ccccccc}
\hline Sample & C (\%) & O (\%) & O/C & Eu (\%) & F (\%) & N (\%) \\
\hline MWCNTs & 99.59 & 0.41 & 0.0041 & - & - & - \\
uMWCNTs & 86.32 & 13.75 & 0.1593 & - & - & - \\
MWCNTs/Eu & 82.67 & 7.44 & 0.0899 & 0.84 & 6.30 & 2.29 \\
uMWCNTs/Eu & 70.02 & 15.57 & 0.2223 & 1.30 & 9.33 & 4.24 \\
\hline
\end{tabular}

The luminescence properties of MWCNTs/Eu and uMWCNTs/Eu nanomaterials were characterized by ethanol dispersion. Figure $5 \mathrm{a}, \mathrm{b}$ show the excitation spectra and emission spectra of MWCNTs/Eu and uMWCNTs/Eu. Figure 5a shows that the excitation wavelength of MWCNTs/Eu is $372 \mathrm{~nm}$ and that of uMWCNTs/Eu is $386 \mathrm{~nm}$. Compared with MWCNTs/Eu, the excitation wavelength peak of uMWCNTs/Eu shifted to the right by $14 \mathrm{~nm}$. It can be seen from the excitation spectra of MWCNTs/Eu and uMWCNTs/Eu that although the excitation characteristic peak positions of MWCNTs/Eu and uMWCNTs/Eu nanomaterials were similar. However, the peak position of uMWCNTs/Eu luminescent materials showed a red shift, indicating that the energy transfer occurred between the $\mathrm{Eu}(\mathrm{TTA})_{3}$ phen and the uMWCNTs. This also indicated that $\mathrm{Eu}(\mathrm{TTA})_{3}$ phen and uMWCNTs bond. In addition, it can be seen from Table 2 that although the luminescence lifetime of MWCNTs $/ \mathrm{Eu}(424.1 \mu \mathrm{s})$ is lower than that of $\mathrm{Eu}(\mathrm{TTA})_{3}$ phen $(515.2 \mu \mathrm{s})$, the luminescence lifetime of uMWCNTs / $\mathrm{Eu}(606.1 \mu \mathrm{s})$ is higher than that of $\mathrm{Eu}(\mathrm{TTA})_{3}$ phen. This indicates that the luminescence lifetime of the complex is improved after the $\mathrm{Eu}(\mathrm{TTA})_{3}$ phen is combined with uMWCNTs.
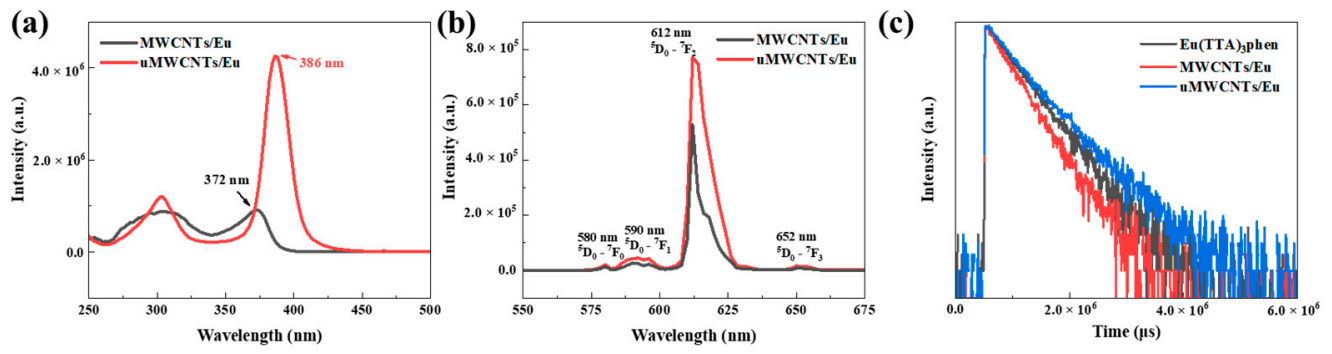

Figure 5. The excitation (a) and emission (b) spectra of MWCNTs/Eu and uMWCNTs/Eu and luminescence decay curves (c) of MWCNTs/Eu, uMWCNTs/Eu and Eu(TTA) $)_{3}$ phen.

Table 2. Luminescence lifetimes of MWCNTs/Eu, uMWCNTs/Eu and Eu(TTA) ${ }_{3}$ phen.

\begin{tabular}{cc}
\hline Sample & Lifetime $(\mu \mathbf{s})$ \\
\hline Eu(TTA) $)_{3}$ phen & 515.2 \\
MWCNTs/Eu & 424.1 \\
uMWCNTs/Eu & 606.1 \\
\hline
\end{tabular}




\subsection{The Strong Enhancement of CER Mechanical Properties by MWCNTs and uMWCNTs}

As shown in Figure 6, the mechanical properties of CER network are enhanced strongly with the addition of MWCNTs or uMWCNTs. The flexural strength and tensile strength of the CER/MWCNTs nanocomposite were $120.75 \mathrm{MPa}$ and $31.17 \mathrm{MPa}$, respectively, and increased by $33.0 \%$ and $24.4 \%$, respectively, compared to the pure CER network. The effect of uMWCNTs is similar to the trend of CER/MWCNTs but the enhancement is more pronounced. It was found that the values of flexural strength and tensile strength of the CER/uMWCNTs nanocomposite were 160.07 MPa and 37.79 MPa, respectively, which are $32.6 \%$ and $21.3 \%$ higher than that of CER/MWCNTs nanocomposites, respectively. Compared with pure CER network, the flexural strength and tensile strength are increased by $76.3 \%$ and $50.9 \%$, respectively.

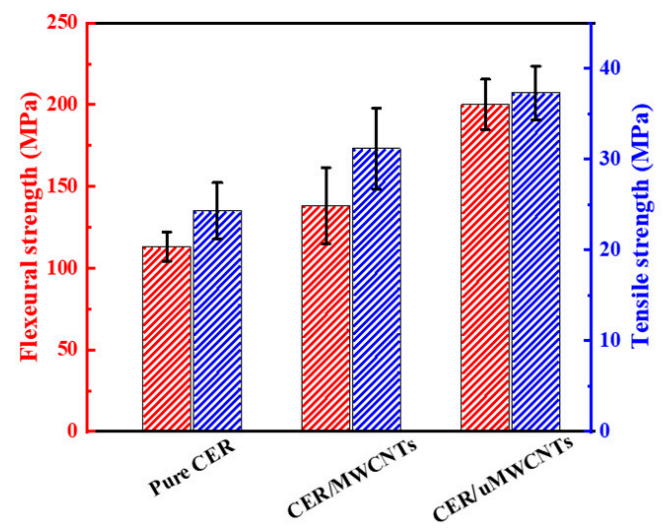

Figure 6. The mechanical properties of pure CER network, CER/MWCNTs and CER/uMWCNTs nanocomposites.

The stress-strain curves for the pure CER network, CER/MWCNTs and CER/uMWCNTs nanocomposites are illustrated in Figure 7 . The difference in mechanical properties observed was closely related to efficiency of chemical interaction of the MWCNTs and uMWCNTs with the CER matrix and dispersing nanofillers in the polymer. Compared with MWCNTs, the uMWCNTs had higher available interface area due to oxidative unzipping of MWCNTs. As shown in Figure 3a, the uMWCNTs possess many groups, such as -OH and $-\mathrm{COOH}$ groups, which react with the $-\mathrm{O}-\mathrm{C} \equiv \mathrm{N}$ group of $\mathrm{CE}$ monomer and growing CER network. Thus, this strong interfacial covalent bonding between uMWCNTs and the CER matrix (see Figure 1) results in more difficulty in sliding uMWCNTs in the CER matrix.

(a)

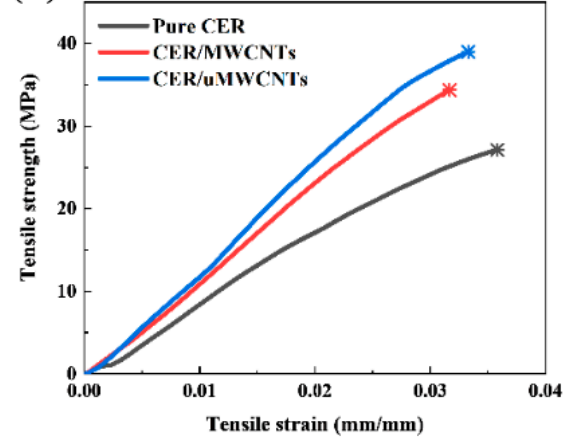

(b)

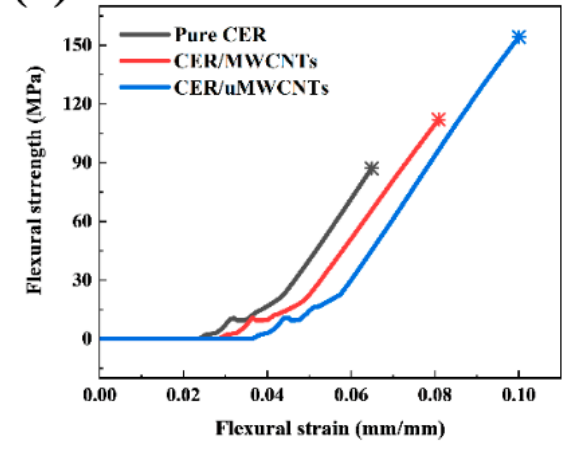

Figure 7. Tensile stress-strain curves (a) and flexural stress-strain curves (b) of the pure CER network, CER/MWCNTs and CER/uMWCNTs nanocomposites.

SEM images of tensile fracture of CER/uMWCNTs nanocomposites were also used to further characterize the dispersibility of uMWCNTs and possible strengthening mecha- 
nism. Figure 8 shows the scanning electron microscope (SEM) cross-sectional image of the nanocomposite. On the one hand, as shown in Figure $8 \mathrm{~b}$ some agglomerations of MWCNTs in in the CER/MWCNTs nanocomposites are observed. The agglomerated regions of MWCNTs were easy to cause crack propagation. However, the dispersion of uMWCNTs in CER/uMWCNTs nanocomposites is more uniform (Figure 8c), which is conducive to the improvement of toughness. On the other hand, it can be seen that the MWCNTs have been pulled out of the matrix. Thus, we supposed the reinforcement effect is mostly pulling-out mechanism because the interaction force between MWCNTs and CER resin matrix was weak. However, the different situation can be found from the CER/uMWCNTs as shown in Figure 8c, in which the broken image of uMWCNTs is shown by the very short bright dots (Figure 8c). Obviously, the binding force between the uMWCNTs and the CER matrix was enhanced due to the increased surface area from unzipping procedure as well as the increased polar oxygen-contained groups at surface of uMWCNTs.

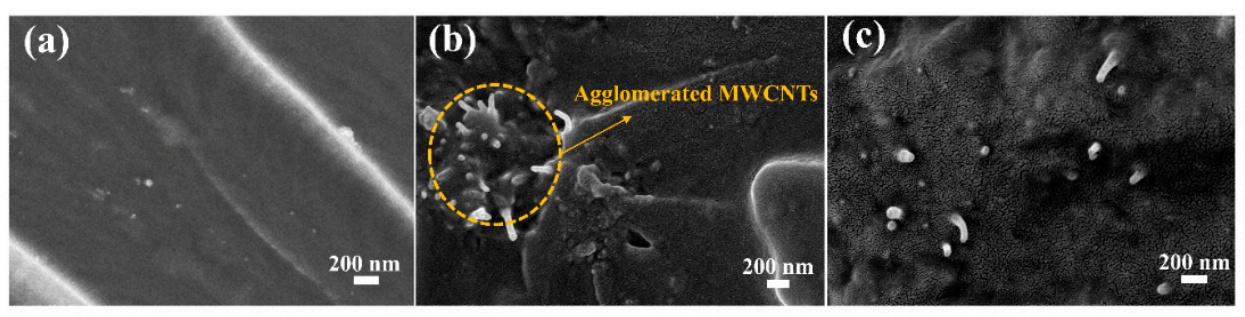

Figure 8. Cross-sectional SEM images for pure CER network (a), and for nanocomposites based on CER/MWCNTs (b) and CER/uMWCNTs (c).

In addition, it was clear that the interfacial adhesion between uMWCNTs and CER matrix was provided not only by Van der Waals forces, but also by the chemical bonding that can bear higher loads. As shown in Figure S1., the characteristic peak of -OH group $\left(3400 \mathrm{~cm}^{-1}\right)$ in CER/uMWCNTs composites disappears. In addition, a new $-\mathrm{C}-\mathrm{N}-\mathrm{C}$ peak appears at $1566 \mathrm{~cm}^{-1}$. Therefore, this paper tends to react the $-\mathrm{OH}$ group and $-\mathrm{COOH}$ group on the surface of uMWCNTs with cyanate ester resin. Furthermore, as shown in Figure 1, the growing CER network grafted covalently to the surface of uMWCNTs via reaction of cyanate groups with-OH groups, forming the CER network coating on a surface of carbon nanotubes, and improving the binding force between carbon nanotubes and matrix polymer. Such a wrapping of CNTs by the CER was observed before [47], which was only possible in systems with high contact between the polymer and MWCNTs.

\subsection{Thermal Property of CER/MWCNTs and CER/uMWCNTs Nanocomposites}

The DSC measurements of CER/MWCNTs and CER/uMWCNTs nanocomposites were performed and the thermograms are given in Figure 9a. It can be seen that the MWCNTs or uMWCNTs were added to the CER monomer, the temperature positions of the peaks were $346.14^{\circ} \mathrm{C}$ or $328.98^{\circ} \mathrm{C}$, respectively. This phenomenon proves that MWCNTs had a strong catalytic effect on CE polymerization and formation of CER network inside the nanocomposites [48]. At the same time, the melting enthalpy $\left(\Delta \mathrm{H}_{\mathrm{m}}\right)$ of CER/MWCNTs was $84.87 \mathrm{~J} / \mathrm{g}$, while this value decreased to $78.02 \mathrm{~J} / \mathrm{g}$ with the addition of uMWCNTs and the enthalpy of formation $\left(\Delta \mathrm{H}_{\mathrm{s}}\right)$ of CER/MWCNTs and CER/uMWCNTs nanocomposites were $718.09 \mathrm{~J} / \mathrm{g}$ or $692.82 \mathrm{~J} / \mathrm{g}$, respectively. The difference between uMWCNTs and MWCNTs was that the surface area of uMWCNT was larger, and there were many polar groups such as $-\mathrm{OH}$ group and $-\mathrm{COOH}$ group on the surface.

The thermal degradation behaviors of the CER/MWCNTs and CER/uMWCNTs nanocomposites are evaluated via TGA (Figure 9b). It can be seen that the degradation mechanism of CER/MWCNTs and CER/uMWCNTs is similar, but the thermal stability is obviously different. The initial decomposition temperature $\left(\mathrm{T}_{\mathrm{di}}\right)$ of the CER/MWCNTs nanocomposite was $338^{\circ} \mathrm{C}$, while the $\mathrm{T}_{\mathrm{di}}$ of $\mathrm{CER} / \mathrm{uMWCNTs}$ nanocomposite was $391^{\circ} \mathrm{C}$, which was $53{ }^{\circ} \mathrm{C}$ higher than that of CER/MWCNTs. The chemical grafting of uMWCNTs 
to the cyanate ester resin matrix improved the adhesion between uMWCNTs and CER matrix and effectively delayed the thermal decomposition of CER network, and thus enhanced the thermal stability of the nanocomposite. In addition, the char residue at $750{ }^{\circ} \mathrm{C}$ of CER/uMWCNTs nanocomposite was slightly higher than that of CER/MWCNTs nanocomposites, but the values were very close. One can concluded that a control of structure of the carbon nanofiller played a very important role of developing new nanocomposites with outstanding thermal property.
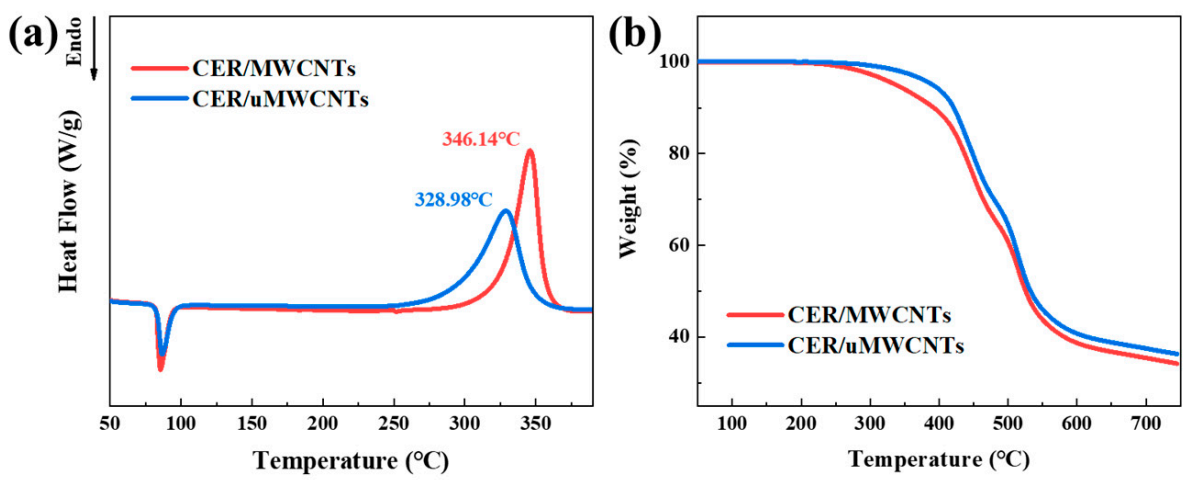

Figure 9. (a) DSC curves of polymerization of initial compositions (indicated in the plot); and (b) TGA curves for the CER/MWCNTs and CER/uMWCNTs nanocomposites.

\subsection{Aging Property of CER/MWCNTs and CER/uMWCNTs Nanocomposites under UV Irradiation}

Some changes in polymer properties, such as mechanical properties, were associated with UV irradiation [49]. IR spectroscopy (Figure 10a) shows the effect of UV irradiation on structure of the composites. Figure 10a displays the FTIR of pure CER, CER/MWCNTs and CER/uMWCNTs nanocomposites before and after UV irradiation. CER network contained many triazine rings formed at polycyclotrimerization of cyanate monomer. The FTIR spectra of the pure cured CER and nanocomposites before and after UV irradiation shows that the peaks of triazine rings at $1570 \mathrm{~cm}^{-1}(-\mathrm{C}-\mathrm{N}=\mathrm{C}-)$ and at $1370 \mathrm{~cm}^{-1}(-\mathrm{O}-\mathrm{C}=\mathrm{N}-)$ remained unchanged. This obviously indicated that neither MWCNTs nor uMWCNTs could change the UV stability of CER, and thus the composites had also obtained excellent UV aging performance.
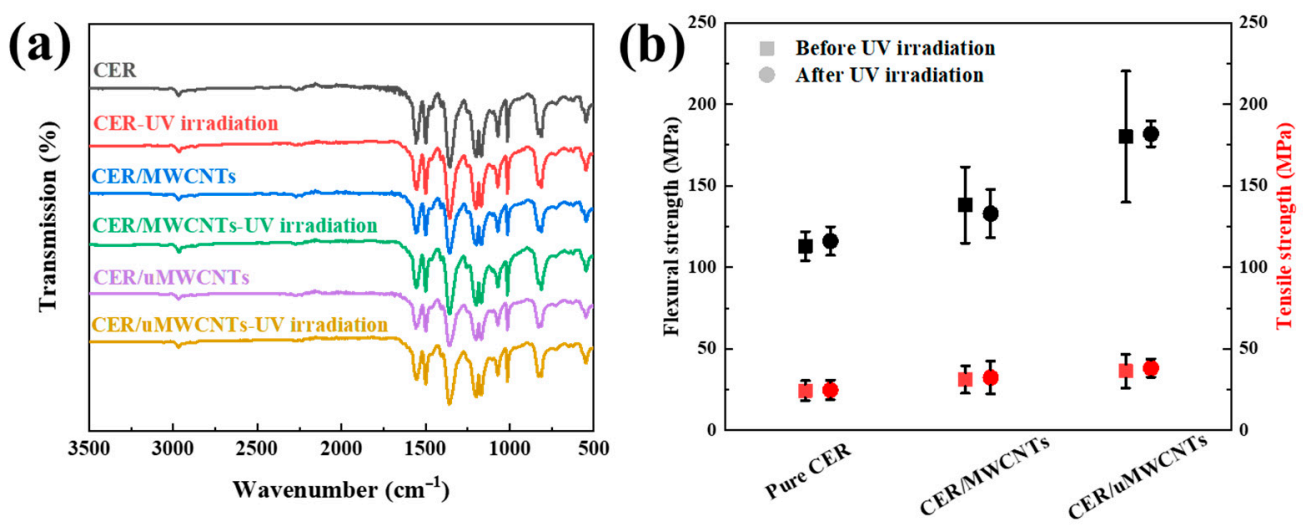

Figure 10. FTIR spectra (a), mechanical properties (b) of the pure CER network, CER/MWCNTs and CER/uMWCNTs nanocomposites before and after UV irradiation.

Figure 10b compares the mechanical properties of the pure CER network, CER/MWCNTs and CER/uMWCNTs nanocomposites before and after UV irradiation. After UV irradiation, the flexural strength of the material equaled 116, 133, $182 \mathrm{MPa}$, respectively that differed just about $2 \%$ from the values measured before UV irradiation. Similarly, the values 
of tensile strength for the pure CER network, CER/MWCNTs resin and CER/uMWCNTs nanocomposites remained unchangeable after UV irradiation $(25,32,38 \mathrm{MPa}$, respectively). This result demonstrate that UV irradiation has little influence on the overall mechanical properties of CER. Since MWCNTs did not change the ultraviolet aging properties of the CER, the CER/uMWCNTs composites with both excellent mechanical properties and ultraviolet aging properties were obtained.

\subsection{Luminescence Property of CER/MWCNTs/Eu, CER/uMWCNTs/Eu Nanocomposites}

Photoluminescence spectra of CER/MWCNTs/Eu, CER/uMWCNTs/Eu nanocomposites were recorded. To improve the photostability of the complex, the complex was first doped with carbon nanotubes and then compounded into the resin matrix (see Section 2.2.1). Luminescence excitation and emission spectra of each component (CER, MWCNTs, uMWCNTs and Eu) of the composites are shown in Figure S2 and Figure 11 shows the excitation and emission spectra of the cured CER doped with MWCNTs/Eu and uMWCNTs/Eu. After curing, the photoluminescence spectra of CER/MWCNTs/Eu, CER/uMWCNTs/Eu in Figure $11 \mathrm{~b}$ distinguished luminescence peaks at $614 \mathrm{~nm}$, indicating the emission characteristics of europium complexes according to the following transition ${ }^{5} \mathrm{D}_{0} \rightarrow{ }^{7} \mathrm{~F}_{2}(614 \mathrm{~nm})$; however, other transitions were concealed. On the other hand, with the formation of CER network in polymerization process, the luminescence emission spectrum of resin gradually appeared as a wide emission band around $500 \mathrm{~nm}$, which indicated the emission of conjugate aromatic network. As shown in Figure 11b, the intensity of resin emission band even overwhelmed that at $614 \mathrm{~nm}$ from the europium complex. At this situation, the emission of europium complex became luminescence behind the visible (FBV), which could impart the embedment of photon quantum information into potential application target. Figure 11a,b indicates that the luminescence intensity of CER/uMWCNTs/Eu is higher than that of CER/MWCNTs/Eu with the same luminescence hybrid material content.
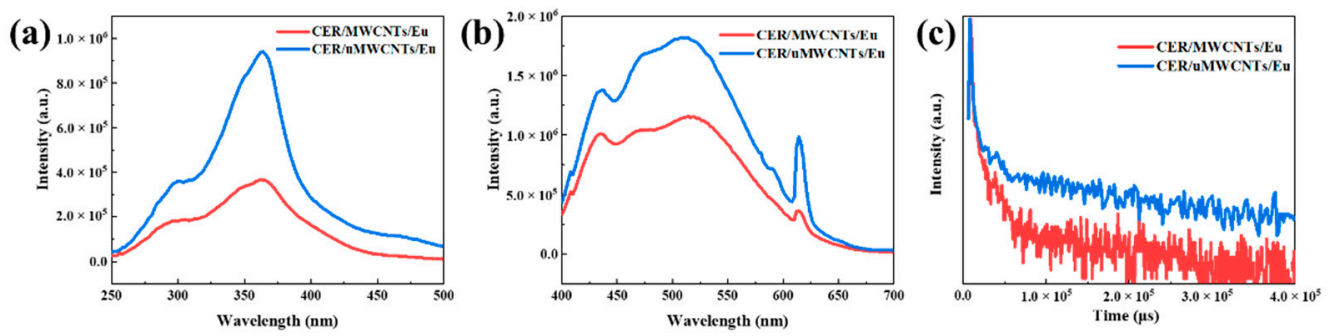

Figure 11. Luminescence excitation (a) and emission (b) spectra and luminescence decay curves (c) of $\mathrm{CER} / \mathrm{MWCNTs} / \mathrm{Eu}, \mathrm{CER} / \mathrm{uMWCNTs} / \mathrm{Eu}$ nanocomposites. Inset shows changes Eu at $\lambda_{\mathrm{ex}}=364 \mathrm{~nm}$, $\lambda_{\mathrm{em}}=614 \mathrm{~nm}$, Scan Slit $=1.50$.

Figure 11c gives the luminescence decay curves of CER/ MWCNTs/Eu, CER/ uMWCNTs/Eu measured at the ${ }^{5} \mathrm{D}_{0} \rightarrow{ }^{7} \mathrm{~F}_{2}$ transition of $\mathrm{Eu}^{3+}$ ion. The luminescence lifetime of CER/MWCNTs/Eu and CER/uMWCNTs/Eu is $8.61 \mu$ s and $186.39 \mu$ s, respectively (shown in Table 3). It can be seen that the addition of uMWCNTs improved luminescence stability of the CER. On the one hand, the surface area of uMWCNTs increased, and at the same time, a lot of functional groups were introduced, which could adsorb more lanthanide complexes. On the other hand, the stabilization effect of oxygen-containing groups such as $-\mathrm{OH}$ and $-\mathrm{COOH}$ groups with lanthanide rare earth complexes improved the energy transfer efficiency from ligand to $\mathrm{Ln}^{3+}$. Although carbon nanotubes could cause partial luminescence quenching, the luminescence quenching efficiency of original MWCNTs was higher than that of unzipped carbon nanotubes [50]. In conclusion, the luminescence intensity of CER/uMWCNTs/Eu is higher than that of CER/MWCNTs/Eu.

It can be seen from Table 3 that the measurement results of quantum yield are corresponding to the luminescence intensity and lifetime results, and one can see that the higher the quantum yield, the higher the luminescence intensity. This is also connected with the specific surface area and surface groups of uMWCNTs. 
Table 3. The lifetime and quantum yield (QY) of CER/MWCNTs/Eu and CER/uMWCNTs/Eu nanocomposites.

\begin{tabular}{ccc}
\hline Sample & Lifetime $(\mu \mathbf{s})$ & QY (\%) \\
\hline CER/MWCNTs/Eu & 8.61 & 1.02 \\
CER/uMWCNTs $/ \mathrm{Eu}$ & 186.39 & 2.12 \\
\hline
\end{tabular}

\section{Conclusions}

In this paper, the luminescence property was innovatively imparted to cyanate ester resin, which also combined with the original thermal properties and the improved mechanical property. With the addition of $0.1 \mathrm{wt} . \%$ of uMWCNTs, the flexural strength and tensile strength of composites increased $59.3 \%$ and $49.3 \%$, respectively. With the same addition, the luminescence property injected into the cyanate resin matrix plays the role of emitting photon signals. The existing broad band of emission in blue makes the luminescence from MWCNTs/Eu an invisible photon signal, and provides the potential photon signal embedment. Another excellent property of the composites is its excellent UV aging performance; neither MWCNTs nor uMWCNTs could change the UV stability of CER. With these multiple functional and mechanical properties, it could be predicted that the thermal-resistant polymer with hybrid luminescent properties will be widely used in sensing in a high-temperature environment.

Supplementary Materials: The following are available online at https:/ /www.mdpi.com/article/10 .3390/ma14154244/s1, Figure S1: FTIR spectra of uMWCNTs, CER/uMWCNTs and pure CER., Figure S2: Luminescence excitation and emission spectra of MWCNTs and uMWCNTs $(\mathbf{a}, \mathbf{b})$, Eu(TTA)3phen $(\mathbf{c}, \mathbf{d})$ and $\operatorname{CER}(\mathbf{e}, \mathbf{f})$.

Author Contributions: Conceptualization, A.F. and J.T.; methodology, L.H.; validation, O.G., P.S., A.F. and J.T.; formal analysis, Y.W.; investigation, N.Y., X.Q., D.Y. and M.C.; resources, A.F. and J.T.; data curation, X.Q., D.Y. and M.C.; writing—original draft preparation, N.Y.; writing—review and editing, A.F. and J.T.; supervision, O.G., P.S.; project administration, Y.W. and L.H.; funding acquisition, J.T. All authors have read and agreed to the published version of the manuscript.

Funding: This work was supported by the (1) National Natural Science Foundation of China (51473082), (2) State Key Project of International Cooperation Research (2017YFE0108300, 2016YFE0110800), (3) Programme for Introducing Talents of Discipline to Universities ("111" plan), (4) double hundred foreign expert project of Shandong Province, and (5) 1st-class discipline programme of Materials Science of Shandong Province, China.

Institutional Review Board Statement: Not applicable.

Informed Consent Statement: Not applicable.

Data Availability Statement: The data presented in this study are available on request from the corresponding author after obtaining permission from an authorized person.

Conflicts of Interest: The authors declare no conflict of interest.

\section{References}

1. Fang, T.; Shimp, D.A. Polycyanate esters: Science and applications. Prog. Polym. Sci. 1995, 20, 61-118. [CrossRef]

2. Hamerton, I. Chemistry and Technology of Cyanate Ester Resins; Chapman \& Hall: Tunbridge Wells, UK, $1994 ;$ pp. 2-3.

3. Tang, Y.; Dong, W.; Tang, L.; Zhang, Y.K.; Kong, J.; Gu, J. Fabrication and investigations on the polydopamine/KH-560 functionalized PBO fibers/cyanate ester wave-transparent composites. Compos. Commun. 2018, 8, 36-41. [CrossRef]

4. Guan, Q.; Yuan, L.; Zhang, Y.; Gu, A.; Liang, G. Improving the mechanical, thermal, dielectric and flame retardancy properties of cyanate ester with the encapsulated epoxy resin-penetrated aligned carbon nanotube bundle. Compos. Part B Eng. 2017, 123, 81-91. [CrossRef]

5. Fainleib, A. Thermostable Polycyanurates: Synthesis, Modification, Structure and Properties; Nova Science Publishers: New York, NY, USA, 2011; pp. 1-364.

6. Motoc, D.L.; Bou, S.F.; Balart, R. Thermal properties comparison of hybrid CF/FF and BF/FF cyanate ester-based composites. J. Therm. Anal. Calorim. 2018, 133, 1-10. 
7. Gu, J.; Dong, W.; Tang, Y.; Guo, Y.; Guo, Z. Ultralow dielectric, fluoride-containing cyanate ester resins with improved mechanical properties and high thermal and dimensional stabilities. J. Mater. Chem. C 2017, 5, 6929-6936. [CrossRef]

8. Spitalsky, Z.; Tasis, D.; Papagelis, K.; Galiotis, C. Carbon nanotube-polymer composites chemistry, processing, mechanical and electrical properties. Prog. Polym. Sci. 2010, 35, 357-401. [CrossRef]

9. Hu, J.; Xiong, X.; Guan, W.; Long, H. Recent advances in carbon nanomaterial-optimized perovskite solar cells. Mater. Today Energy 2021, 21, 100769. [CrossRef]

10. Zhang, S.; Kang, L.; Wang, Z.; Tong, L.; Yang, L.; Wang, Z.; Qi, K.; Deng, S.; Li, Q.; Bai, X.; et al. Arrays of horizontal carbon nanotubes of controlled chirality grown using designed catalysts. Nature 2017, 543, 234-238. [CrossRef] [PubMed]

11. Yoong-Ahm, K.; Hiroyuki, M.; Masahito, K.; Takuya, H.; Yutaka, K.; Morinobu, E. Stacking nature of the catalytic chemical vapor deposition-derived double-walled carbon nanotubes. J. Nanosci. Nanotechnol. 2019, 6, 3321-3324.

12. Wu, H.; Gu, A.; Liang, G.; Yuan, L. Novel permittivity gradient carbon nanotubes/cyanate ester composites with high permittivity and extremely low dielectric loss. J. Mater. Chem. 2011, 21, 14838-14848. [CrossRef]

13. Han, C.; Gu, A.; Liang, G.; Yuan, L. Carbon nanotubes/cyanate ester composites with low percolation threshold, high dielectric constant and outstanding thermal property. Compos. Part A Appl. Sci. Manuf. 2010, 41, 1321-1328. [CrossRef]

14. Fainleib, A.; Bardash, L.; Boiteux, G.; Grigoryeva, O. Thermosetting cyanate ester resins filled with CNTs. In Advances in progressive thermoplastic and thermosetting polymers, perspectives and applications; Mamunya, Y., Iurzhenko, M., Eds.; Tehnopress editura: Iasi, Romania, 2012; Volume 10, pp. 379-424.

15. Fainleib, A.; Bardash, L.; Boiteux, G. Catalytic effect of carbon nanotubes on polymerization of cyanate ester resins. Exp. Polym. Lett. 2009, 3, 477-482. [CrossRef]

16. Bardash, L.; Boiteux, G.; Grykien, R.; Glowacki, I.; Pastorczak, M.; Ulanski, J.; Fainleib, A. Electrical conductivity of polymer/carbon nanotubes nanocomposites at low temperatures. Polym. J. 2018, 40, 230-239. [CrossRef]

17. Li, P.; Li, T.; Yan, H. Mechanical, Tribological and heat resistant properties of fluorinated multi-walled carbon nanotube/bismaleimide/cyanate resin nanocomposites. J. Mater. Sci. Technol. 2017, 33, 118-122. [CrossRef]

18. Lu, C.; Yuan, L.; Guan, Q.; Liang, G.; Gu, A. Optimizing Ply Pattern and Composition of Layered Composites Based on Cyanate Ester, Carbon Nanotube and Boron Nitride: Toward Ultralow Dielectric Loss and High Energy Storage. J. Phys. Chem. C 2018, 122, 5238-5247. [CrossRef]

19. Mei, H.; Xia, J.; Zhang, D.; Li, H.; Bai, Q.; Cheng, L. Mechanical properties of carbon fiber reinforced bisphenol A dicyanate ester composites modified with multiwalled carbon nanotubes. J. Appl. Polym. Sci. 2017, 134, 45100. [CrossRef]

20. Pisani, W.A.; Radue, M.S.; Patil, S.U.; Odegard, G.M. Interfacial modeling of flattened CNT composites with cyanate ester and PEEK polymers. Compos. Part B Eng. 2021, 211, 108672. [CrossRef]

21. Yu, M.F.; Lourie, O.; Dyer, M.J.; Moloni, K.; Kelly, T.F.; Ruoff, R.S. Strength and breaking mechanism of multiwalled carbon nanotubes under tensile load. Science 2016, 287, 637-640. [CrossRef]

22. Kosynkin, D.V.; Higginbotham, A.L.; Sinitskii, A.; Lomeda, J.R.; Dimiev, A.; Price, B.K.; Tour, J.M. Longitudinal unzipping of carbon nanotubes to form graphene nanoribbons. Nature 2009, 458, 872-876. [CrossRef] [PubMed]

23. Wang, Y.; Shi, Z.X.; Yin, J. Unzipped multiwalled carbon nanotubes for mechanical reinforcement of polymer composites. J. Phys. Chem. C 2010, 114, 19621-19628. [CrossRef]

24. Chen, S.; Sun, J.; Li, G. Study on the modification of cyanate ester resin used hydroxylated multi-walled carbon nanotubes. New Chem. Mater. 2018, 46, 95-99.

25. Zhang, Z.; Sun, Z.; Yao, J.; Kosynkin, D.V.; Tour, J.M. Transforming carbon nanotube devices into nanoribbon devices. J. Am. Chem. Soc. 2009, 131, 13460-13463. [CrossRef]

26. Amanda, L.; Higginbotham, D.V.K.; Sinitskii, A.; Sun, Z.; Tour, J.M. Lower-Defect Graphene Oxide Nanoribbons from Multiwalled Carbon Nanotubes. Am. Chem. Soc. 2010, 4, 13460-13463.

27. Han, J.-H.; Kim, C.-G. Low earth orbit space environment simulation and its effects on graphite/epoxy composites. Compos. Struct. 2006, 72, 218-226. [CrossRef]

28. Xie, F.; Liu, L.; Gong, X.; Huang, L.; Leng, J.; Liu, Y. Effects of accelerated aging on thermal, mechanical and shape memory properties of cyanate-based shape memory polymer: Ivacuum ultraviolet radiation. Polym. Degrad. Stab. 2017, 138, 91-97. [CrossRef]

29. Cui, G.; Chen, S.; Jiang, B.; Zhang, Y.; Qiu, N.; Satoh, T.; Kakuchi, T.; Duan, Q. Synthesis and characterization of novel thermoresponsive fluorescence complexes based on copolymers with rare earth ions. Opt. Mater. 2013, 35, 2250-2256. [CrossRef]

30. Silva, C.; Bispo, A.G., Jr.; Lima, S.; Pires, A.M. Eu3+ complex/polymer films for light-emitting diode applications. Opt. Mater. 2019, 96, 109323. [CrossRef]

31. Itankar, S.G.; Dandekar, M.P.; Koinkar, P.M.; Kondawar, S.B. Influence of Polymer in Photoluminescence Properties of Electrospun Eu3+ Doped Polymer Nanofibers; Springer: Singapore, 2020; Volume 242.

32. Mosse, I.S.; Sodisetti, V.R.; Coleman, C.; Nc Ube, S.; Bhattacharyya, S. Tuning Magnetic Properties of a Carbon NanotubeLanthanide Hybrid Molecular Complex through Controlled Functionalization. Molecules 2021, 26, 563. [CrossRef]

33. Mohanraj, J.; Armaroli, N. Luminophores and Carbon Nanotubes: An Odd Combination? J. Phys. Chem. Lett. 2013, 4, 767-778. [CrossRef] [PubMed]

34. Wu, H.X.; Cao, W.M.; Wang, J.; Yang, H.; Yang, S.P. Coating multi-walled carbon nanotubes with rare-earth complexes by an in situ synthetic method. Nanotechnology 2008, 19, 345701. [CrossRef] 
35. Yoo, H.J.; Kim, K.H.; Yadav, S.K.; Cho, J.W. Effects of carbon nanotube functionalization and annealing on crystallization and mechanical properties of melt-spun carbon nanotubes/poly(ethylene terephthalate) fibers. Compos. Sci. Technol. 2012, 72, 1834-1840. [CrossRef]

36. Li, Y.; Jiao, J.; Yan, P.; Liu, L.; Wang, J.; Wang, Y.; Huang, L.; Liu, J.; Belfiore, L.A.; Tang, J. Synthesis and tunable photoresponse for core-shell structured $\mathrm{NaGdF}_{4}: \mathrm{Yb}, \mathrm{Er} @ S i O_{2} @ \mathrm{Eu}(\mathrm{TTA})_{3}$ Phen nanocomplexes. Scr. Mater. 2018, 152, 1-5. [CrossRef]

37. Shi, J.; Wang, Y.; Huang, L.; Lu, P.; Sun, Q.; Wang, Y.; Tang, J.; Belfiore, L.A.; Kipper, M.J. Polyvinylpyrrolidone Nanofibers Encapsulating an Anhydrous Preparation of Fluorescent $\mathrm{SiO}(2)(-) \mathrm{Tb}(3+)$ Nanoparticles. Nanomaterials 2019, 9, 510. [CrossRef] [PubMed]

38. Li, H.; Gu, J.; Liu, C.; Wang, D. Thermal and mechanical properties of cyanate ester resin modified with acid-treated multiwalled carbon nanotubes. High Perform. Polym. 2018, 30, 38-46. [CrossRef]

39. Li, H.; Wang, D.; Qu, C.; Liu, Z.; Feng, H.; Su, K. Preparation and performances of bisphthalonitrile resin and novolac cyanate ester resin blends. Polym. Bull. 2019, 76, 5649-5660. [CrossRef]

40. Jana, S.; Zhong, W.H. Effects of Hygrothermal Conditions and UV Radiation on UHMWPE Fibers/Nanofiber-Epoxy Composites. J. Compos. Mater. 2016, 41, 2897-2914. [CrossRef]

41. Yuen, S.-M.; Ma, C.-C.M.; Lin, Y.-Y.; Kuan, H.-C. Preparation, Morphology and properties of acid and amine modified multiwalled carbon nanotube/polyimide composite. Compos. Sci. Technol. 2007, 67, 2564-2573. [CrossRef]

42. Zhang, Y.; Song, Y.; Gan, Y.; Feng, M.; Zhan, H. Broadband nonlinear optical and optical limiting effects of partially unzipped carbon nanotubes. J. Mater. Chem. C 2015, 3, 9948-9954. [CrossRef]

43. Kumar, S.; Raj, S.; Sarkar, K.; Chatterjee, K. Engineering a multi-biofunctional composite using poly(ethylenimine) decorated graphene oxide for bone tissue regeneration. Nanoscale 2016, 8, 6820-6836. [CrossRef] [PubMed]

44. Ferrari, A.C.; Robertson, J. Interpretation of raman spectra of disordered and amorphous carbon. Phys. Rev. B 2000, 61, 14095-14107. [CrossRef]

45. Ferrari, A.C.; Meyer, J.C.; Scardaci, V.; Casiraghi, C.; Lazzeri, M.; Mauri, F.; Piscanec, S.; Jiang, D.; Novoselov, K.S.; Roth, S. Raman spectrum of graphene and graphene layers. Phys. Rev. Lett. 2006, 97, 187401. [CrossRef]

46. Pei, S.; Wei, Q.; Huang, K.; Cheng, H.M.; Ren, W. Green synthesis of graphene oxide byseconds timescale water electrolytic oxidation. Nat. Commun. 2018, 9, 145. [CrossRef] [PubMed]

47. Bardash, L.; Fainleib, A.; Grigoryeva, O.; Boiteux, G.; Ulanski, J. Effect of Carbon Nanotubes on Formation Process, Structure and Properties of Nanocomposites Based on Thermostable Crosslinked Polycyanurates. Ukr. Chem. J. 2013, 79, $58-68$.

48. Santhosh Kumar, K.S.; Reghunadhan Nair, C.P.; Ninan, K.N. Investigations on the cure chemistry and polymer properties of benzoxazine-cyanate ester blends. Eur. Polym. J. 2009, 45, 494-502. [CrossRef]

49. Hill, L.W.; Korzeniowski, H.M.; Ojunga-Andrew, M.; Wilson, R.C. Accelerated clearcoat weathering studied by dynamic mechanical analysis. Prog. Org. Coat. 1994, 24, 147-173. [CrossRef]

50. Liu, Y.; Liu, C.-Y.; Liu, Y. Investigation on fluorescence quenching of dyes by graphite oxide and graphene. Appl. Surf. Sci. 2011, 257, 5513-5518. [CrossRef] 